\title{
Striking a balance
}

\author{
An interview with Sharon R. Long, plant biologist and Professor of Biology at Stanford University, USA
}

EMBO reports: We are in the midst of a host of international meetings-the United Nations Climate Summit and the G20 Summit-that seek to discuss climate change and alternative sources of energy. With the current emphasis on renewable energy, do you think that plant science will enjoy a boost in funding and attention?

Sharon Long: In the United States I think we have already seen an increased emphasis on supporting energy research within plant biology and microbiology. From the standpoint of creating more biomass and in terms of plant properties, the focus for research funding has been on plant functions that relate to photosynthesis, biomass production and to converting plant material into biofuels. I think there are probably more areas related to plant biology that are not yet covered, but these are the early days of our new administration-it's been less than a year-and I expect that more opportunities will come along.

\section{"Science has something to say about an issue at the heart of some GMO opposition: that people generally misunderstand the concept of risk"}

EMBO reports: Producing more biomass or increasing the efficiency of photosynthesis will probably require the genetic modification (GM) of plants if they are to become an important source of energy production. Research in this area has stalled in Europe in the light of public opposition to genetically modified organisms (GMOs), and there is growing criticism of GM crops in the USA. Do you see that this could become a problem in the USA in the long run?
Long: The optimization of plants for energy production will likely involve genetic modification. I think that biotechnology has great potential for improving energy production and sustainability. But there are molecular methods short of plant transformation, which can also contribute. For example, traditional breeding assisted by molecular markers can be a very fruitful approach. Coming back specifically to GMOs, I think the technology is very promising. It can offer a great deal for sustainable agriculture-which is something I am quite interested in-in addition to being useful for particular energy-related functions. I hope people will see biotechnology as a tool that can be used for purposes other than large-scale commodity crop production.

About public resistance to genetically modified organisms, I think it's not as big a topic here in the USA as it is in Europe. From my point of view, I think it's a great shame that some anti-technology groups spread fear about GMOs by using statements that are deceptive, and I hope scientists do everything they can to counter this misinformation. Our job as plant scientists is to give clear and impartial advice. I don't think we should be pro-biotech or anti-biotech, I think we should stick to giving the very best and most accurate information that we can. The anti-GMO movement in Europe operates at several levels; some of the concerns relate to history and culture. I think people have deeply held values about farms and food traditions. This is an example of a consideration that lies outside of science, and that needs to be discussed on its own terms.

\section{EMBO reports: What role should scientists} have in these debates?

Long: Science has something to say about an issue at the heart of some GMO opposition: that people generally misunderstand

\section{"The more you bring people into the conversation, the closer you get to having everybody well informed, which is the basis for making appropriate policy decisions"}

the concept of risk. The general public seems to think that for something to be 'safe' it must be certified as having no risk. Scientists know that probability doesn't go to zero. As scientists, we quantify risk instead of saying there is no risk, so people are led to believe that somehow genetic transformation is 'dangerous' because scientists refuse to say it has zero risk. I think better education of the public would help with this issue. In fact, if I had one wish it would be that everyone should be educated about probability and statistics in high school. I know that psychologists have done some fascinating studies on how people perceive risk. For example, they minimize major risks like smoking and they focus on things that are actually not high risks such as flying in an airplane. It is part of human nature to have some fuzziness about what is risky and what isn't. Unfortunately, some of the anti-GM advocacy groups play on that misunderstanding of risk.

It's appropriate for governments to establish regulations for GMOs. I've commented already that scientists should be objective, should give fair and accurate advice, and should be respectful of cultural considerations that are not science's purview. In turn, I feel that regulation of GMOs should be based on honest scientific assessments of risk and not on myths or pseudo-science. I also hope that citizens in their turn will try to be well informed. I hope that they will come to see the amazing benefits that can be offered by plant 
biotechnology and to understand that this tool can support sustainability and can mitigate environmental risk.

EMBO reports: Our understanding is that all decisions on GMOs in the USA are made on scientific grounds, but that the President has directed legislators to begin to canvas and include public opinion and the input of non-governmental organizations in these decisions?

Long: Yes and I think that's a good idea. The more you bring people into the conversation, the closer you get to having everybody well informed, which is the basis for making appropriate policy decisions. That also works for the government, which gets its rights and its powers from the people.

EMBO reports: Do you think this will lead to a change in the regulation of GMOs? Currently, for example, products in the USA that contain GMOs are not labelled as such, whereas in Europe they absolutely must be labelled.

Long: There are really two issues here. The regulation of plant biology and crops is one thing. Labelling rules for food come under a different part of the government's regulatory apparatus. Decisions about this issue also should be decided by government on behalf of the people. We live in a democracy and if citizens want GM products to be labelled, then there should be labels. I think the problem is that people can become convinced that labels indicate a distinction of something that is good versus not good. Advertising can play on that in misleading ways. I rather suspect that anti-GMO activists would like to have labels so they can use it to claim that modified organisms are unsafe, and to pretend that there are 'scientific' reasons behind it. And as long as people are inappropriately afraid or mistrustful of genetic modification, then food manufacturers are probably going to be reluctant to put labels onto their products.

I compare this to labels for kosher. It's a particular way of preparing food that has nothing to do with science but rather with culture and tradition. It's very important to people who keep kosher; they need labels to guide them, and their preferences merit our respect and support. I look at organic and other labels in a similar way. When we think of our foods, we have some standards

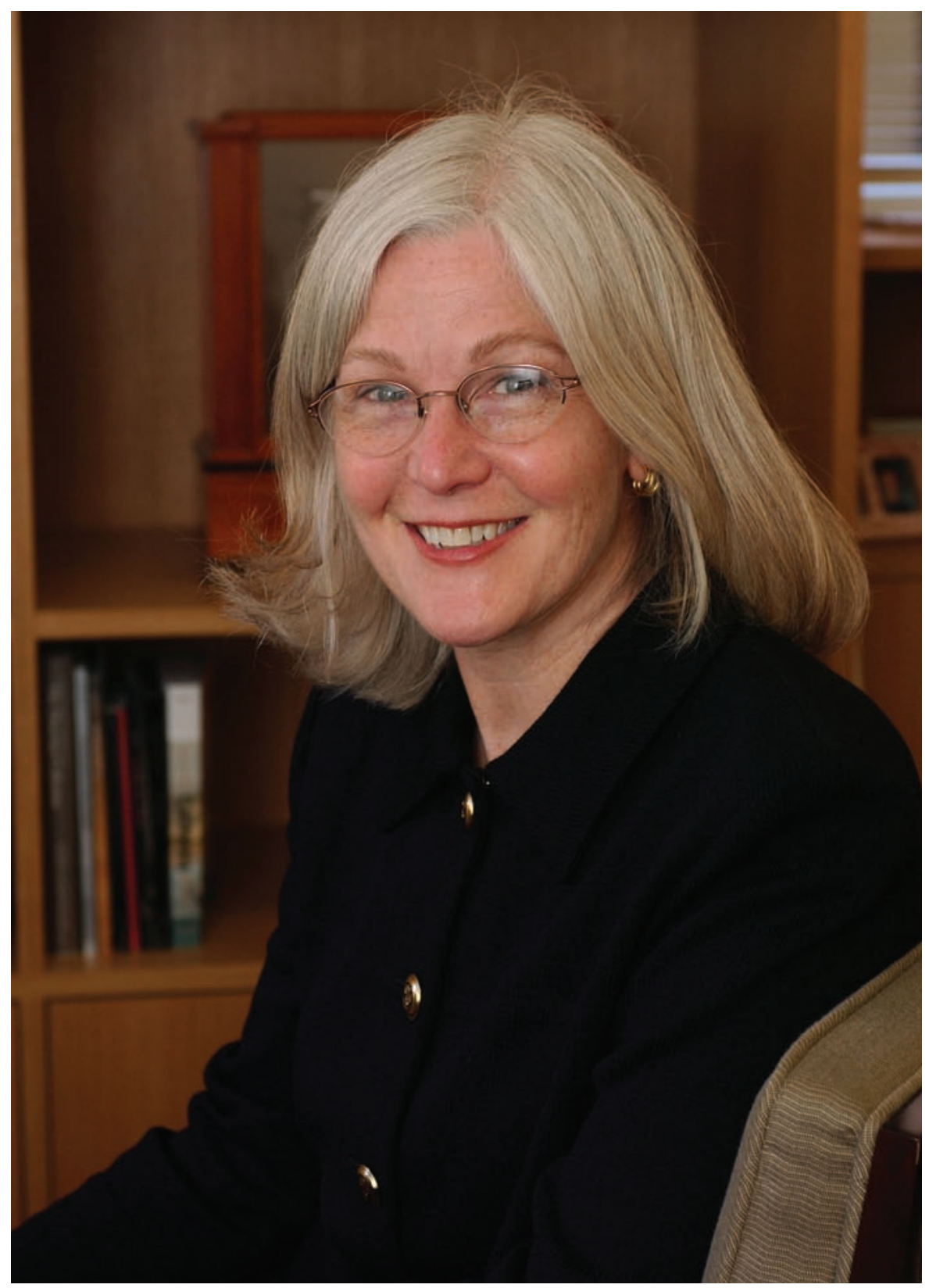

that may arise from scientific measurements, such as content and safety, and others that relate to cultural importance, such as organic or non-GM. In each case, a label should indicate how a product measures with respect to those standards. But what I think is unacceptable is for culturally-based labels to be presented as if there is a scientifically 'better' or 'safer' message implied. Also, the idea that something can only be labelled GM-free if it has absolutely zero GM content doesn't make any sense to me as a scientist or as a practical person. Again, this brings us back to misunderstanding and lack of education, and to statements from anti-biotechnology groups that are at best disingenuous and at worst deceptive.

EMBO reports: Plant biotechnology is increasingly commercialized and many products are developed by private companies. Do you think this creates problems in terms of the freedom of academic researchers to operate if companies hold important patents?

Long: From my own experience at Stanford, both as a scientist and as the Dean of the Faculty of Humanity and Science for six 
years, I believe the job of a university is to protect intellectual honesty and openness. A university should not allow students or non-profit funds to be used to benefit a commercial entity in an unfair way, nor should a university accept contract research that is then restricted. At Stanford we scrutinize any interaction between a faculty member's academic work and company sponsorship or company participation. No Stanford professor is allowed to accept funding that restricts publication or communication of results. No Stanford professor is allowed to work on something that's classified as 'secret'. That policy actually originated from doing research for the government but it applies the same way to people who work for a chemical company or a biotech company or a computer optics company. If a Stanford faculty member or student patents a finding, the university holds that patent and the university might give a temporary exclusive license. But in the end, it needs to be open. In terms of intellectual property and public access to research results, Stanford takes a very proactive, public-oriented position. I think that's what all universities should do.

\section{"I certainly think that the administration honours science, takes it seriously, wants to see science as a partner at the table"}

EMBO reports: You are working on nitrogen fixation. Since the process was discovered decades ago, it has been the dream of plant scientists to use it to replace artificial fertilizers, but we haven't gotten far with it. Do you think that it will be possible one day to use nitrogen fixation to replace fertilizer use?

Long: I think this is a great example of how both traditional and biotechnological approaches can be used to make a big difference in agriculture. Traditionally, symbiosis is of course a time-honoured way of undertaking sustainable agriculture, whether it's through crop rotation or co-cropping or using legumes for green manure. And it's known that many legumes have features that benefit both agriculture and natural ecosystems. Many legumes can establish nitrogen-fixing symbioses with naturally occurring soil bacteria; however, the combinations of plants and bacteria are sometimes not optimal. Using molecular methods and markers, we can try to find symbioses that have better tolerance of salinity, better tolerance of other extreme conditions or of the presence of metals and so forth. The fact that we have so many sequences and markers means that we can make huge advances in terms of the basic biology. Due to high natural diversity out there in soils, we have a lot of choices for plants and microbes to use in a traditional setting.

Now let me explain how biotechnology might be used in two ways. One is modifying the bacteria; the other is modifying the plant. Each has great potential and each has some problems. With respect to the plant, one wouldn't have to transform rice or corn in order to improve symbiosis. We can work with legumes themselves, making improved variants of their own genes, to optimize nitrogen fixation. On the bacterial side, it's known which genes encode the enzymes that convert nitrogen into a form useable by the plant. There may be natural variants among existing bacteria, or one could construct variants, with better kinetic properties. I think that's one way we might envision the use of biotechnology.

EMBO reports: Given the complexity of nitrogen fixation, do you think it would be possible to use this more generally in plants?

Long: Can you transfer symbiosis properties into non-symbiotic organisms? I think we can start to do those experiments, because studies of model plants as well as of crops have identified a number of the plant genes that are required for the establishment of symbiosis. So we can start experiments on signalling. A major question is, how do the bacteria cause the plant to form a root nodule? We can start to ask whether we could transfer the response apparatus to rice or another plant.

However, symbiotic nitrogen fixation is a finely tuned physiological process. Some factors underlying what makes nitrogen fixation effective in one legume and not in another are not related to signal transduction or nodule formation. Rather, these factors might include the flow rate for carbohydrates from the shoot to the root and bacteria. Controlling a rate of flow is not easy to manipulate with a single gene. I don't think we understand all the genes that control such processes even within well-studied model organisms, so we are far away from knowing how to transfer these properties from one organism to another. Put another way, we could ask, even if you could get nonlegumes to form root nodules, how do you assure that the crop's productivity is helped? That's a big challenge in terms of basic biology. In recent years, there has been relatively little research on physiology - that is, quantitative studies of plant function including growth rates and metabolic rates. I think we need more of such research in plant biology in general, and the question of how one would optimize or transfer symbiosis brings that question into prominence.

\section{"In the case of a natural phenomenon where our research has limited predictive power or quantification of behaviour [...] I feel science should step back from taking pride of place"}

EMBO reports: We also want to talk about your role as one of President Obama's scientific advisors. Do you think that the President has so far lived up to his preelection promise to restore science's proper place in politics and decision making?

Long: First, I should clarify that I was an advisor during the campaign and during the transition, but my duties as advisor ended when the appointed science advisors stepped in. Presently, I'm active as a member of the Council for the National Academy of Sciences. On the Council, we interact with policy makers, provide advice and help to identify individuals who might be able to serve in the government. I am quite excited by the direction in which the nation is going. I think that President Obama's administration has made really positive steps to get high-quality science advice and they have appointed outstanding scientists to major positions of responsibility. It's hard to overstate how great it is.

EMBO reports: In terms of the money available for making good on those election promises, has the financial crisis had much of an impact on science funding?

Long: I think the stimulus package certainly has a great deal for science in it. Energy and the National Institutes of Health both got a lot of attention in the stimulus package. 
Other than that, the administration is asking Congress for appropriations, which will be very helpful for science. That's a legislative process and it takes longer. I certainly think that the administration honours science, takes it seriously, wants to see science as a partner at the table. You pointed out earlier that the President also wants public conversations about technology and to include more of society in decision making. I think that's a good thing because you don't have an 'us versus them' situation; everybody is sharing concerns and information. I have confidence that people want to do the right thing and will be very fair and open towards promising safe technological advances.

EMBO reports: With that positive frame of mind and looking back, to what extent did the Bush administration damage the role of science in society and politics?

Long: I believe that the official actions of the Bush administration were very unfortunate in several ways. Climate research is a good example where responsible, careful science being done by government scientists was not allowed to be put forth. That was a terrible blow to the scientific integrity of the government agencies. The other example I pick is with respect to science appointments and funding, for example, for stem cells. It was based on politics and not science, and was an unfortunate effect of playing to a political constituency. This decision ended up damaging a vibrant and important part of frontier investigations in cell biology and in life sciences as a whole.

EMBO reports: What do you think should be the exact role of scientists in the political process, now that you have a sciencefriendly administration? Should there be even more scientists involved; should there be even more scientific advice in political decision making?

Long: I may answer this in a slightly different way. I feel very strongly about science being allowed to speak in areas where science has a real authority and where science has answers. That's why I am upset about the way in which careful, reliable science about global climate change, for example, was in effect suppressed. Equally important, however, I feel that scientists should realize that there are areas where science does not have the final say, and that other voices need to be heard and respected. An example would be deterministic statements about how the mind works and the possible implications for legal issues. In my view, scientists should not be the ones making the call on that. In the case of a natural phenomenon where our research has limited predictive power or quantification of behavioursuch as the case of consciousness and the puzzle of whether there is free will - I feel science should step back from taking pride of place.

\section{"It does a disservice both to science and to religion to put religious-based ideas into a science curriculum"}

EMBO reports: Do you think there should be more plant scientists in President Obama's advisory team?

Long: I would love to see more plant biology represented. Of course, we have Barbara Schaal [from Washington University in Saint Louis, MO, USA]. She is a plant biologist and member of the President's Council of Advisors on Science and Technology and she represents our community. I would like to see much more high-calibre plant biology advice in the National Science Foundation, the US Department of Agriculture, the Department of Energy and so forth. We also need plant biologists in administrative posts, who are at the same level scientifically as the great scientists who are advising the government in other areas.

EMBO reports: What do you think is the right approach to address the influence of religion on scientific knowledge, particularly with regard to Intelligent Design. Do you think that scientists are the right people to tackle these sorts of problems?

Long: I think that this has to be a partnership. It does a disservice both to science and to religion to put religious-based ideas into a science curriculum. It is not very respectful of religion, which is a spiritual dimension of the human experience. I talked earlier about what makes science a science: one needs to be able to make reproducible, quantifiable observations that have predictive power. The spiritual life is not something that you can put a number on. To try to portray a spiritual belief as science distracts from the main point of spirituality, in my view.

Here is another area where I think antiscience people don't play by the same rules as scientists do. Anti-science activists, such as anti-evolution advocates, will play on statements by scientists that to a layperson may sound like there is a big controversy about whether evolution is valid. Of course there are big questions and debates. How would an individual make a distinct academic life for themselves except by doing new research, and arguing with other people about genuine mysteries? But people who aren't scientists don't quite understand that. So many words have different meaning or connotation in science: we speak of the 'atomic theory' but no one means they don't think atoms exist. This theory is not a guess; it's the best model for dealing with the form and function of matter. Same with evolutionary theory: not a guess, but the best scientific model for explaining relatedness, differences, adaptations and the historical dimension of life. I hope that there will be more conversations, and better education and more respect for both sides. I am a practicing Christian and I am a scientist. But I am not a fundamentalist, and in fact most people of faith in this country are not fundamentalists. I hope scientists will have respect for religion and vice versa. In my view, there is plenty of room for both spirituality and science in our culture.

The National Academy of Scientists came out with a publication on this topic about a year and a half ago. I was the Council member in charge of the final review and edit. The book is called Science, Evolution and Creationism. It is meant as a handbook to help scientists and non-scientists to talk about evolution and to counter anti-science, anti-evolution statements. It is used broadly; there are many people who were eager to get hold of this book. I think that's a sign that a majority of people really do want to move forward with science education about evolution, among other things. I hope that's a good sign for the future.

EMBO reports: Professor Long, many thanks for the interview.

\section{The interview was conducted by Holger Breithaupt and Samuel Caddick.}

Received 16 December 2009; accepted 16 December 2009; published online 22 January 2010

EMBO reports (2010) 11, 82-85.

doi:10.1038/embor.2009.285 